\title{
A comparison of behavioral and pharmacological interventions to attenuate reactivated fear memories
}

\author{
Roque I. Ferrer Monti, ${ }^{1,2,3,4,5,6}$ Joaquín M. Alfei, ${ }^{1,2,6}$ Matías Mugnaini, ${ }^{1}$ \\ Adrián M. Bueno, ${ }^{1}$ Tom Beckers, ${ }^{2}$ Gonzalo P. Urcelay, ${ }^{3}$ and Victor A. Molina ${ }^{4}$ \\ ${ }^{1}$ Laboratorio de Psicología Experimental, Facultad de Psicología, Universidad Nacional de Córdoba, Enfermera Gordillo y Enrique Barros, \\ Ciudad Universitaria, (5000) Córdoba, Argentina; ${ }^{2}$ Department of Psychology, KU Leuven, 3000 Leuven, Belgium; ${ }^{3}$ Department of \\ Neuroscience, Psychology \& Behaviour, University of Leicester, Leicester, LE1 7HA, United Kingdom; ${ }^{4}$ IFEC-CONICET, Departamento de \\ Farmacología, Facultad de Ciencias Químicas, Universidad Nacional de Córdoba, Haya de la Torre y Medina Allende, Ciudad \\ Universitaria, (5000) Córdoba, Argentina; ${ }^{5}$ Instituto Hebb de Salud Mental, Martín Coronado 3282 (5009), Córdoba, Argentina
}

Two experiments using rats in a contextual fear memory preparation compared two approaches to reduce conditioned fear: (1) pharmacological reconsolidation blockade and (2) reactivation-plus-extinction training. In Experiment 1, we explored different combinations of reactivation-plus-extinction parameters to reduce conditioned fear and attenuate reacquisition. In Experiment 2, memory reactivation was followed by extinction training or administration of midazolam (MDZ) (vs. vehicle) to reduce conditioned fear and attenuate spontaneous recovery. We found both treatments to be equally effective in both experiments. This study suggests that parameters leading to memory destabilization during reactivation are critical to observe long-lasting effects of MDZ or reactivation plus extinction.

Anxiety disorders (i.e., general anxiety disorder, phobias, and posttraumatic stress disorder) are most effectively treated with exposure therapy, which consists of the controlled presentation of feared stimuli or contexts, eventually leading to fear reduction (Craske et al. 2008). Experimental extinction is a laboratory model for exposure therapy, based on the assumption that one of the multiple components of anxiety disorders are associative memories driving the expression of conditioned responses (CRs), acquired through pairing of a conditioned stimulus (CS) with an aversive unconditioned stimulus (US). Following this rationale, one of the multiple effects of exposure therapy is the reduction of CR expression as a consequence of repeated presentation of the CS without the US (extinction). Clinical and laboratory evidence supports these assumptions (Scheveneels et al. 2016). Indeed, the benefits and pitfalls of exposure therapy are observed in extinction learning. For example, a major challenge for exposure therapy is relapse, or the return of fear after treatment in a variety of circumstances that represent a change from the (internal or external) context of exposure training to that of testing (Urcelay 2012). This is captured by the notion that extinction training promotes new (contextdependent) inhibitory learning, rather than the modification of the original fear memory (Bouton 2002). As a result, after extinction training the original memory coexists with an extinction memory, and the retrieval context (or other critical cues present at the time of retrieval) determines which memory controls behavior at a given time (Bouton 2004). Great research efforts have been devoted to enhancing extinction learning and maximizing the benefits of exposure therapy (Urcelay et al. 2009a,b), but the endurance of the original fear memory always makes the return of fear a possibility (Craske et al. 2008, 2014).

Prospects for a more robust prevention of return-of-fear come from studies that target fear memory more directly (Beckers and Kindt 2017). Retrograde amnesia can be induced for discrete con-

\footnotetext{
${ }^{6}$ These authors contributed equally to this work.

Corresponding authors: r.ferrermonti@gmail.com, joaquin.alfei@ kuleuven.be

Article is online at http://www.learnmem.org/cgi/doi/10.1101//m.045385.117
}

solidated memories (Misanin et al. 1968), if properly reactivated (Finnie and Nader 2012). The reconsolidation hypothesis states that reactivation of a consolidated memory trace can induce its destabilization and subsequent reconsolidation during a timelimited period: the "reconsolidation window" (Nader et al. 2000). It is currently unknown whether the retrograde amnesia for reactivated and destabilized memories reflects interference with memory storage or retrieval mechanisms. However, there is strong experimental evidence supporting retrieval-failure explanations (Briggs and Olson 2013; Guisquet-Verrier et al. 2015; see Riccio et al. 2006 for a review). Regardless, clinical applications of reconsolidation interference are currently the focus of several research programs (Beckers and Kindt 2017).

Two main approaches have been reported to disrupt or permanently alter reactivated Pavlovian CS-US memories: pharmacological reconsolidation blockade (Nader et al. 2000) and the reactivation-plus-extinction procedure $(\mathrm{R}+\mathrm{E})$ (Monfils et al. 2009). The former consists in pharmacologically disrupting memory reconsolidation, while the latter entails conducting extinction training during the reconsolidation window. Previous work in our laboratory has been aimed at better understanding the psychological variables that determine the effectiveness of these manipulations. Using contextual fear conditioning (CFC) in rats, we previously reported that permanent reduction of fear through the $\mathrm{R}+\mathrm{E}$ procedure requires that memories are destabilized during reactivation (Piñeyro et al. 2014). We also reported that memory destabilization, and therefore the possibility of pharmacologically blocking the reconsolidation process, requires the occurrence of an US temporal prediction error during memory reactivation (Alfei et al. 2015), a result reported by other groups in other experimental preparations (Pedreira et al. 2004; Díaz-Mataix et al. 2013).

(C) 2017 Ferrer Monti et al. This article is distributed exclusively by Cold Spring Harbor Laboratory Press for the first 12 months after the full-issue publication date (see http://learnmem.cshlp.org/site/misc/terms.xhtml). After 12 months, it is available under a Creative Commons License (AttributionNonCommercial 4.0 International), as described at http://creativecommons. org/licenses/by-nc/4.0/. 
Although administering amnestic drugs and conducting extinction training upon memory reactivation have both been shown to induce robust reduction of conditioned fear and prevent fear recovery, it is currently unknown which one is more effective. To our knowledge, only one study has addressed this problem, using a human differential fear conditioning protocol (Soeter and Kindt 2011). In that report, both the $\beta$-blocker propranolol (PROP) or extinction training were applied after CS reactivation, with R + PROP preventing several forms of fear reappearance (spontaneous recovery, reinstatement, reacquisition, and fear generalization). The $\mathrm{R}+\mathrm{E}$ procedure prevented only spontaneous recovery, failing to attenuate reinstatement, reacquisition, or generalization. One possibility is that extinction trials felt short to fully alter the reactivated memory, as suggested by the authors. Another possible explanation for those results is that different interference procedures might require different reactivation conditions to alter the target memory. However, in that study $\mathrm{R}+\mathrm{PROP}$ and $\mathrm{R}+\mathrm{E}$ were compared across two experiments, rather than in the same experiment. Hence, a direct comparison in a single experiment of both strategies has not yet been conducted, and the question of the relative efficacy of each approach remains unanswered. The experiments presented here were designed to compare directly both strategies (Exp. 2), after determining the critical role of reactivation conditions to induce different plasticity process over the target memory (Exp. 1).

We used CFC in rats and midazolam (MDZ), a fast-acting positive modulator of the GABA-A receptor known to interfere with the consolidation and reconsolidation of aversive memories (Bustos et al. 2006; Kroon and Carobrez 2009), and compared it with experimental extinction following reactivation. Because memory reactivation can lead to different mnemonic outcomes (mere retrieval, destabilization, or the formation of a novel memory trace), and we have previously shown that memory destabilization during reactivation is critical for the success of the $\mathrm{R}+\mathrm{E}$ procedure (Piñeyro et al. 2014), our first step was to investigate different reactivation conditions combined with extinction. This was done to identify the optimal reactivation conditions for the $\mathrm{R}+\mathrm{E}$ procedure before comparing it against $\mathrm{R}+\mathrm{MDZ}$. We evaluated reactivation conditions that our previous work suggested would induce mere retrieval (no CR reduction and insensitivity to MDZ when tested $24 \mathrm{~h}$ after reactivation), destabilization (no CR reduction in control conditions but vulnerability to MDZ), insensitivity to MDZ (neither CR reduction nor MDZ vulnerability), and extinction (CR reduction that can be blocked by MDZ).

Subjects were naïve, adult male Wistar rats (60-65 d old, weighing 270-320 g at experimental onset), bred in our own colony in the Laboratorio de Psicología Experimental, Facultad de Psicología, Universidad Nacional de Córdoba, Argentina. Animals were housed in standard laboratory Plexiglas cages (60 $\mathrm{cm}$ long $\times 40 \mathrm{~cm}$ wide $\times 20 \mathrm{~cm}$ high) in groups of 3-4 per cage. Food and water were available ad libitum. Animals were maintained on a 12-h light-dark cycle (lights on at 8 a.m.), at room temperature of $21^{\circ} \mathrm{C}-23^{\circ} \mathrm{C}$ (following standards of the NIH Guide for the Care and Use of Laboratory Animals). The number of animals and their suffering was kept to the minimum possible to achieve the goals of this research. The experimental apparatus used to conduct the CFC was a 24 long $\times 22$ wide $\times 22$-cm high Plexiglas chamber with opaque gray walls and a removable transparent ceiling, the floor consisting of 20 parallel stainless steel grid bars each measuring $3 \mathrm{~mm}$ in diameter, spaced $1 \mathrm{~cm}$ apart and connected to a device to provide adjustable footshocks (the Automatic Reflex Conditioner 7501, Ugo Basile). All experiments were videotaped from above for later off-line analyses. Freezing behavior was used as an index of fear, defined as the total absence of body and head movements except for that associated with breathing (Blanchard and Blanchard 1969). Freezing was scored minute by minute with a stopwatch by an observer blind to the experimental condition of each animal, and expressed as percent of time (in seconds). Inter-observed reliability was previously established with a different set of data (Pearson's $r=0.95$ ). Data were analyzed with " $t$ " tests, one-way repeated-measures or mixed ANOVAs, followed by the Tukey's HSD test as post hoc analyses for significant effects reported by the ANOVAs.

In Experiment 1, rats were submitted to a CFC protocol that yields a fear memory with a precise temporal expectation of US arrival (Alfei et al. 2015). Animals were handled and habituated to the experimenter during three consecutive days. A day later, animals were introduced in the experimental apparatus for $1 \mathrm{~min}$ (preshock period), after which two footshocks (1-mA, 3-sec duration intershock interval of $30 \mathrm{sec}$ ) were delivered. Immediately after, animals were returned to the home cage. Seventy-two hours later, memory reactivation was achieved by reexposing animals to the conditioned context, without footshocks. Four nonreinforced reactivation lengths were used in order to trigger different mnemonic processes: $30 \mathrm{sec}$ (mere retrieval), 2 min (destabilization), $6 \mathrm{~min}$ (insensitive state), or $15 \mathrm{~min}$ (extinction). Following a 10-min interval in the home cage after reactivation, half of the animals in the $30 \mathrm{sec}, 2 \mathrm{~min}$, and $6 \mathrm{~min}$ conditions were submitted to a second context exposure of $14.5,13$, and 9 min, respectively, to achieve a total of 15 min of exposure in all animals (hence, accomplishing conditions prone to induce fear extinction according to Alfei et al. 2015). The other half had the second exposure omitted, to serve as controls. The group submitted to a straight 15-min exposure did not receive a second exposure trial, as conditions to induce extinction had already been met. After $24 \mathrm{~h}$, subjects were submitted to a reacquisition procedure, consisting in the administration of a single $0.5-\mathrm{mA}$ shock for $3 \mathrm{sec}$ after a $93-\mathrm{sec}$ preshock period, to recover the extinguished CR (Piñeyro et al. 2014; Ferrer Monti et al. 2016). An additional control group, without any previous training, was included to quantify the amount of CR expression produced by the US used during the reacquisition procedure. The final test, a 5-min context reexposure without shock, was conducted a day later. Groups were labeled as follows: R $30 \mathrm{sec} /$ Ext $14.5 \mathrm{~min}$ $(n=7)$; control: R $30 \mathrm{sec}(n=6) ; \mathrm{R} 2 \mathrm{~min} / \mathrm{Ext} 13 \mathrm{~min}(n=7)$; control: $\mathrm{R} 2 \min (n=6) ; \mathrm{R} 6 \mathrm{~min} / \mathrm{Ext} 9 \min (n=6)$; control: $\mathrm{R} 6 \min (n=6)$; Ext 15 min $(n=6)$; Reacq Only $(n=7)$ (see Fig. $1 \mathrm{~A})$.

Results: Unpaired, two-tailed $t$-tests revealed no significant differences at reactivation when comparing each of the groups that received both $\mathrm{R}+\mathrm{E}$ to its respective control $(P>0.05$ in all cases, Fig. 1B). The Ext 15-min group lacked an identical control during reactivation and was not compared at this phase. A one-way ANOVA (group as factor) on the preshock period of the reacquisition phase yielded a significant effect of group $\left(F_{(7,43)}=12.41, P=0.00000, \eta^{2} p\right.$ $=0.66$ ). Post hoc analyses revealed that the groups submitted to $\mathrm{R}+$ $\mathrm{E}$ and the 15-min extinction group expressed significantly less fear than the control groups (R $30 \mathrm{sec}, \mathrm{R} 2 \mathrm{~min}$, and R $6 \mathrm{~min}$ ) and similar levels of fear as the untrained Reacq Only group. In other words, combining reactivation and extinction as well as straight extinction reduced CRs relative to reactivation controls (Fig. 1C). However, $24 \mathrm{~h}$ after reacquisition, the only group to still show similar low levels of freezing as the Reacq Only group was the R $2 \mathrm{~min} /$ Ext 13 min group, with both groups expressing significantly lower levels of CR than the rest. This was confirmed by a one-way ANOVA $\left(F_{(7,43)}=36.98, P=0.00000, \eta^{2} p=0.85\right)$ and by the post hoc analyses. Hence, the $\mathrm{R}+\mathrm{E}$ procedure prevented rapid $\mathrm{CR}$ reacquisition only when reactivation was timed such as to be optimal for inducing memory destabilization (Fig. 1D). This confirms, with different parameters, our previous findings regarding the critical role of memory destabilization prior to extinction in order to observe superior effects of $\mathrm{R}+\mathrm{E}$ over regular extinction training (Piñeyro et al. 2014). Our results are in line with the idea that memory destabilization is achieved by the induction of a temporal prediction error; 

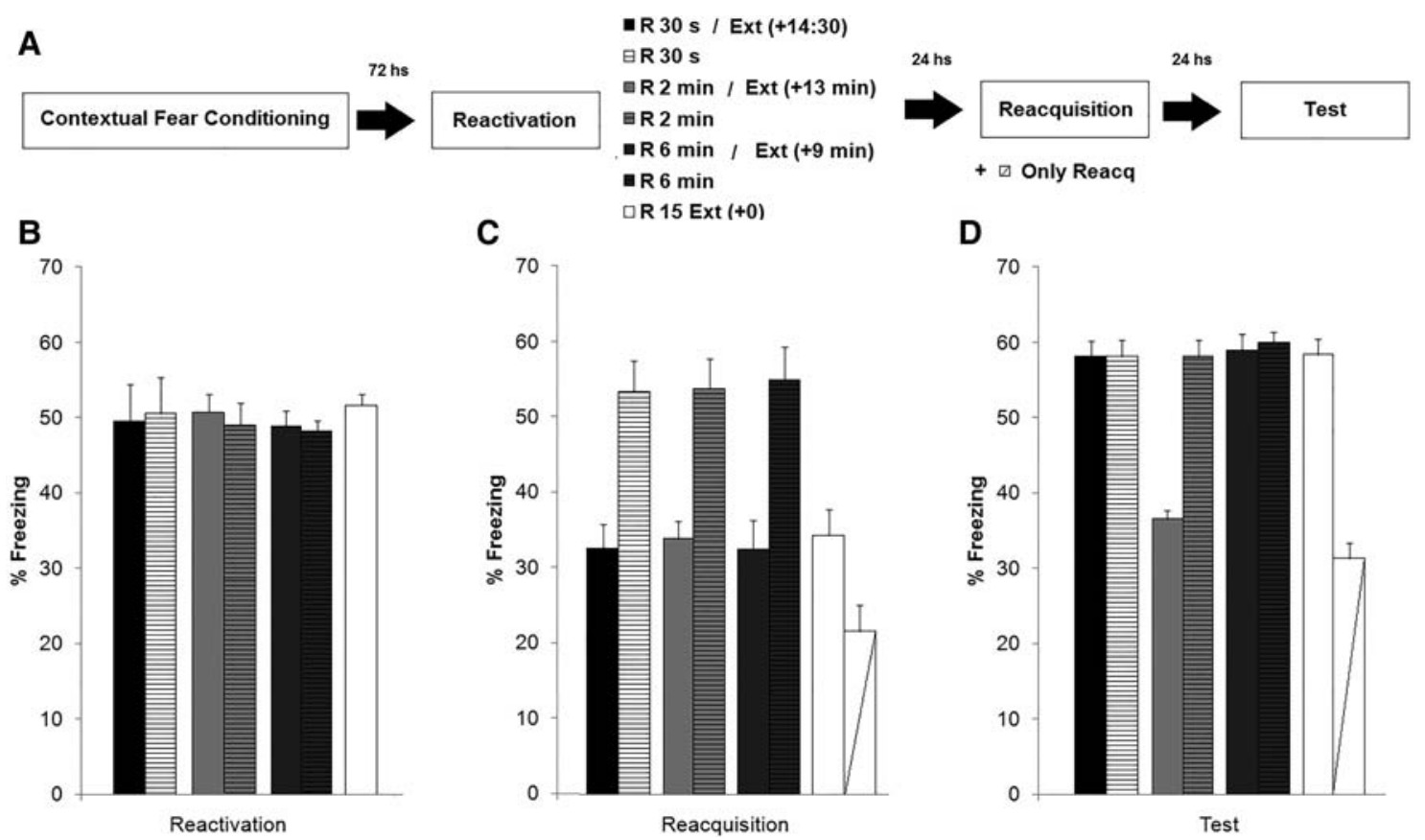

Figure 1. Experiment $1(A)$. Three days after training, contextual fear memory was reactivated through $30 \mathrm{sec}, 2 \mathrm{~min}, 6 \mathrm{~min}$, or $15 \mathrm{~min}$ of reexposure to the training context $(B$, showing total freezing percent during each reactivation length). Half of the subjects in each group were submitted to a second context exposure (after a 10-min interval in the home cage) to complete the 15 min needed to achieve extinction, except for those submitted to a straight $15 \mathrm{~min}$ of reactivation (data not shown, but see Fig. 3 showing similar data for Experiment 2). After $24 \mathrm{~h}$, all groups were submitted to a reacquisition protocol ( $C$ : preshock freezing). At this stage, a group of untrained (naive) animals was added, which only received reacquisition. All groups were tested a day later $(D)$. None of the groups completing $15 \mathrm{~min}$ of context reexposure at reactivation differed from an untrained group in preshock freezing to the context $24 \mathrm{~h}$ later (during reacquisition). However, $1 \mathrm{~d}$ after reacquisition, the group submitted to reactivation conditions apt to trigger memory destabilization was the only one comparable to the previously untrained controls. Data show the mean \pm SEM of percentage time spent freezing during reactivation, preshock period of reacquisition and test.

the discrepancy between information presented during acquisition (i.e., US onset at the first minute) and memory reactivation (i.e., US absence at the expected time), which renders the memory unstable and vulnerable to pharmacological (Alfei et al. 2015) or behavioral interventions (present results). It is important to note that every group submitted to both reactivation and extinction had actually a total of $15 \mathrm{~min}$ of context reexposure between both instances. Hence, any difference among groups cannot be attributed to differences in total time spent in the context without US delivery, but to the particular effect of memory reactivation. In fact, we have previously observed that separating the first and second context reexposures for a longer delay $(6 \mathrm{~h})$ prevents the effect of extinction (or other interference procedures as $\mathrm{MDZ}$ or contrasting emotional information) over the destabilized memory, presumably because the reconsolidation window is closed by that time (Piñeyro et al. 2014; Alfei et al. 2015; Ferrer Monti et al. 2016).

Experiment 2 was designed to directly compare the effects of MDZ administration and extinction training after reactivation $(\mathrm{R}+$ $\mathrm{MDZ}$ versus $\mathrm{R}+\mathrm{E})$. Rats were trained as in Experiment 1 and memory was reactivated $72 \mathrm{~h}$ later. Three reactivation lengths were used: 2 min (destabilization), 6 min (insensitive state), and 15 min (extinction). Animals in each reactivation condition were randomly assigned to one of three treatments: MDZ $3 \mathrm{mg} / \mathrm{kg}$ (i.p) (Alfei et al. 2015), saline (SAL), or a second context reexposure (after a 10-min break in the home cage) to complete the 15 min necessary to achieve extinction (EXT, which lasted 13 or $9 \mathrm{~min}$ for the groups that received 2 or 6 min of context exposure during initial reactivation, respectively). Animals submitted to a straight $15 \mathrm{~min}$ reactivation had the second reexposure omitted, because this length of exposure leads to extinction (Alfei et al., 2015; Piñeyro et al. 2014). Subjects were then tested and retested for $5 \mathrm{~min}$ in the con- ditioned context (without US) 1 and $7 \mathrm{~d}$ following memory reactivation, respectively. For all groups, $n=6$ (see Fig. $2 \mathrm{~A}$ ).

Results: Although all experimental conditions were run simultaneously, reactivation lengths were different for the 2, 6, and 15-min conditions. Accordingly, reactivation data were analyzed separately (treatment as factor), with no significant differences between treatments for any of the three reactivation conditions $(P>$ 0.05 in all cases). Furthermore, a one-way mixed ANOVA on the minute-by-minute freezing data for the three groups that completed $15 \mathrm{~min}$ of context reexposure (group and time as factors) revealed no effect of group $\left(F_{(2,14)}=0.00, P=0.99348\right)$, a significant effect of time $\left(F_{(14,196)}=3.25, P=0.00011, \eta^{2} p=0.18\right)$, but no interaction $\left(F_{(28,196)}=0.58, P=0.95078\right)$. Post hoc analyses revealed that freezing peaked by the second minute, as previously reported for animals trained under these conditions (Alfei et al. 2015; see Fig. 3). Regarding the effects of the different treatments, a mixed 3 (reactivation: 2,6 , or $15 \mathrm{~min}$ ) $\times 3$ (treatment: $\mathrm{EXT}, \mathrm{MDZ}$, or $\mathrm{SAL}) \times 2$ (session: test and retest) ANOVA revealed significant effects of reactivation $\left(F_{(2,45)}=12.18, P=0.00006, \eta^{2} p=0.35\right)$, treatment $\left(F_{(2,45)}=13.54, P=0.00002, \eta^{2} p=0.37\right)$, session $\left(F_{(1,45)}=\right.$ 27.49, $\left.P=0.00000, \eta^{2} p=0.37\right)$, reactivation $\times$ treatment $\left(F_{(4,45)}=\right.$ 9.71, $\left.P=0.00001, \eta^{2} p=0.46\right)$, reactivation $\times$ session $\left(F_{(2,45)}=9.52\right.$, $\left.P=0.00036, \quad \eta^{2} p=0.29\right)$, treatment $\times$ session $\left(F_{(2,45)}=8.51, \quad P=\right.$ $\left.0.00073, \eta^{2} p=0.27\right)$ and critically, a reactivation $\times$ treatment $\times$ session interaction $\left(F_{(4,45)}=4.48, P=0.0039, \eta^{2} p=0.28\right)$. To break down the three-way interaction, mixed ANOVAS were performed for each reactivation condition separately (treatment and session as factors). For the 2-min condition, the ANOVA revealed a significant effect of treatment $\left(F_{(2,16)}=26.08, P=0.00001, \eta^{2} p=0.76\right)$, no effect of session $\left(F_{(1,16)}=0.00, P=0.924\right)$, and no interaction $\left(F_{(2,16)}=0.33, P=0.71781\right)$. Post hoc analyses revealed that MDZ 


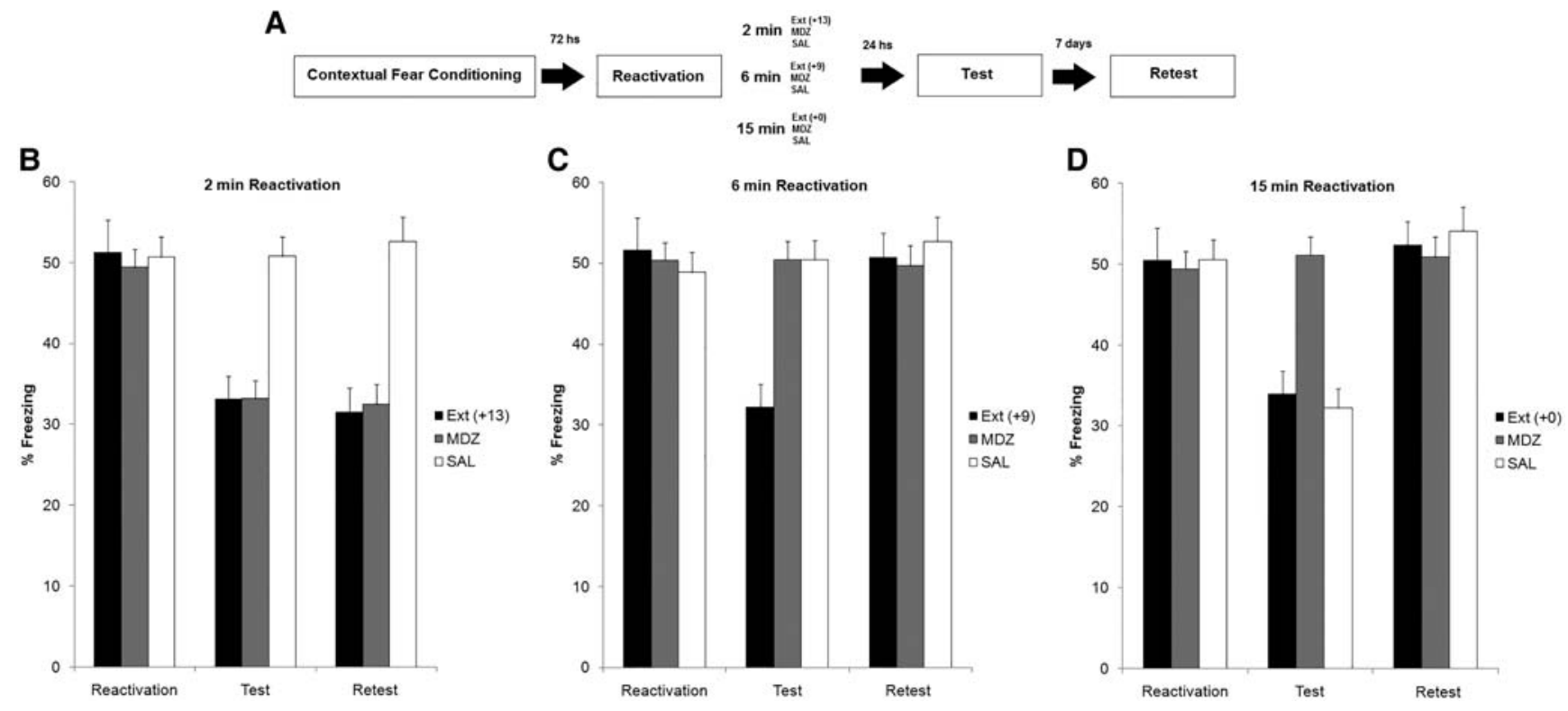

Figure 2. Experiment $2(A)$. Three days after training, contextual fear memory was reactivated during $2 \min (B), 6 \min (C)$, or $15 \min (D)$ by reexposure to the training context. Subjects in each condition received either $3 \mathrm{mg} / \mathrm{kg}$ of midazolam (MDZ), saline (SAL), or a second reexposure (after a 10-min break in the home cage) to achieve conditions for inducing extinction (EXT). One day and $1 \mathrm{wk}$ later, all groups were subjected to a 5 -min test and retest in the training context. MDZ and EXT were equally effective at reducing CR and attenuating spontaneous recovery when reactivation was optimal for inducing destabilization (2-min reactivation). In contrast, MDZ was unable to reduce CR and EXT failed to prevent spontaneous recovery when reactivation was not attuned to inducing destabilization (6-min reactivation). Finally, straight extinction (15-min reactivation) reduced CR at test but failed to prevent spontaneous recovery. Extinction was blocked by MDZ in this condition. Data show the mean \pm SEM of percentage time spent freezing during reactivation, test and retest.

and EXT reduced CR compared with SAL at test, and a week later (attenuated spontaneous recovery; Fig. 2B). For the 6-min condition, the ANOVA revealed a significant effect of treatment $\left(F_{(2,15)}\right.$ $\left.=4.88, P=0.02325, \eta^{2} p=0.39\right]$ and session $\left(F_{(1,15)}=13.36, P=\right.$ $\left.0.00234, \eta^{2} p=0.47\right)$ and a significant interaction $\left(F_{(2,15)}=10.68\right.$, $\left.P=0.00131, \eta^{2} p=0.58\right)$. Post hoc analyses revealed that EXT reduced CR expression compared with MDZ and SAL at test, but this difference disappeared a week later (spontaneous recovery; Fig. 2C). For the 15-min condition, the ANOVA revealed a significant effect of treatment $\left(F_{(2,14)}=4.23, P=0.003634, \eta^{2} p=0.37\right)$ and session $\left(F_{(1,14)}=21.36, P=0.0004, \eta^{2} p=0.60\right)$ and a significant interaction $\left(F_{(2,14)}=5.92, P=0.01368, \eta^{2} p=0.45\right)$. Post hoc analyses showed that MDZ blocked the CR reduction observed for the EXT and SAL groups at test, but this difference disappeared again after a week (spontaneous recovery; Fig. 2D).

In summary, this experiment: (a) revealed that $\mathrm{R}+\mathrm{MDZ}$ and $\mathrm{R}+\mathrm{E}$ are equally effective at reducing fear CRs, provided that memory destabilization is achieved during reactivation; (b) confirms that, unlike standard extinction, $\mathrm{R}+\mathrm{E}$ prevents spontaneous recovery if destabilization is triggered before extinction (Piñeyro et al. 2014); (c) suggests that the beneficial effects of $\mathrm{R}+\mathrm{E}$ are not due to a differential pattern of CR expression during reexposure to feared cues; and (d) replicates previous findings from different groups, including ours, that hint to the existence of a particular mnemonic state between destabilization and extinction memory formation which is insensitive to pharmacological and behavioral interference
(Briggs and Olson 2013; Flavell and Lee 2013; Merlo et al. 2014; Sevenster et al. 2014; Alfei et al. 2015).

These findings suggest similar effectiveness of pharmacological and behavioral interventions to modify reactivated aversive memories. This is partially at odds with the report of Soeter and Kindt (2011), who found that the $\mathrm{R}+\mathrm{E}$ procedure prevented spontaneous recovery but failed to attenuate reinstatement and reacquisition. Here we find that the $\mathrm{R}+\mathrm{E}$ procedure attenuates both spontaneous recovery (Exp. 2) and reacquisition (Exp. 1). These somewhat contrasting results might reflect species (human vs. rats), task (cued vs. contextual fear) or other procedural differences, such as the retention interval to observe spontaneous recovery
Total context re-exposure

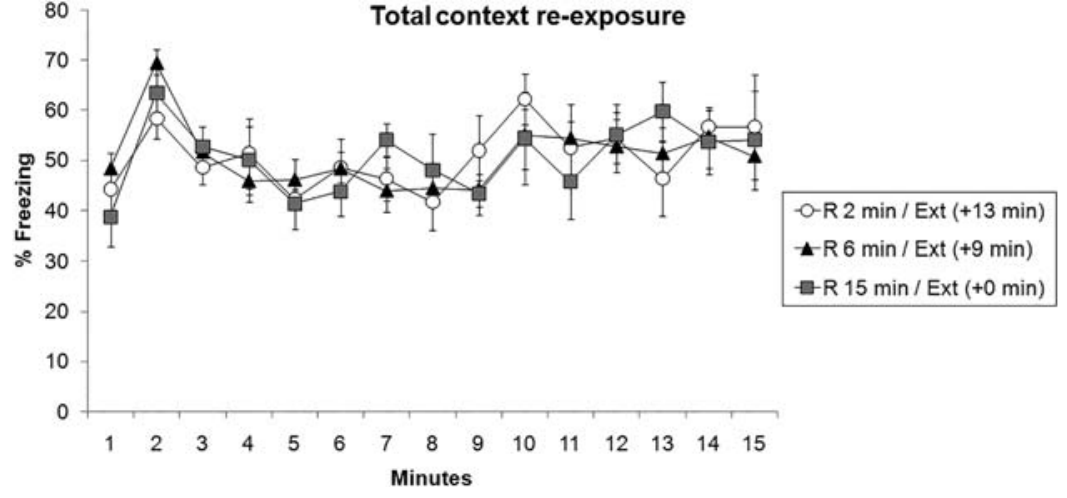

Figure 3. Experiment 2. Data show the mean $\pm S E M$ of percentage time spent freezing during the entire 15 min of context reexposure for groups R $2 \mathrm{~min} /$ Ext $13 \mathrm{~min}$, R $6 \mathrm{~min} /$ Ext $9 \mathrm{~min}$, and R $15 \mathrm{~min}$ (straight extinction). For all groups, the peak of CR expression was at min 2. There was no difference between groups at any time during context reexposure. Hence, attenuated spontaneous recovery for the $\mathrm{R} 2 \mathrm{~min} /$ Ext $13 \mathrm{~min}$ group cannot be attributed to enhanced $\mathrm{CR}$ reduction during context reexposure. 
after extinction ( 1 vs. $7 \mathrm{~d}$ ). One important feature of the present results is the suggestion that memory reactivation in itself does not necessarily lead to memory destabilization; prediction error at the time of reactivation is a critical moderator of the occurrence of post-retrieval malleability (Exton-McGuinness et al. 2015; Fernández et al. 2016). In line with this notion, we used reactivation conditions previously shown in pharmacological work to induce destabilization through a temporal prediction error (Alfei et al. 2015). Although the importance of prediction error has been acknowledged in the reactivation-extinction literature (Golkar et al. 2012; Oyarzún et al. 2012; Auber et al. 2013; Hutton-Bedbrook and McNally 2013; Ishii et al. 2015; Fricchione et al. 2016), only a few studies have actually used reactivation conditions that were optimally suited for inducing memory destabilization (as deduced from pharmacological blockade of memory reconsolidation in independent experiments). In those studies, CR recovery was fully or partially prevented (Flavell et al. 2011; Rao-Ruiz et al. 2011; Soeter and Kindt 2011; Piñeyro et al. 2014). Lack of prediction error at the time of reactivation might help explain why some groups have failed to replicate the results originally reported by Monfils et al. (2009) (see Auber et al. 2013; Exton-Mcguinness et al. 2015 for discussion). Furthermore, it is worth mentioning that two recent reports on hazardous drinkers also suggest a critical role of memory destabilization, through the induction of prediction errors (via guided expectancy violations about alcoholic-related cues), for observing endurable effects of reappraisal and counterconditioning (Das et al. 2015; Hon et al. 2016). Similar results have recently been reported in animals as well (Haubrich et al. 2015; Ferrer Monti et al. 2016).

Overall, the findings presented in this report suggest that behavioral and pharmacological interventions can be equally effective to reduce conditioned fear. Extended to clinical settings, this implies that patients reluctant to take psychiatric drugs might choose exposure therapy. Similarly, patients not willing to reexperience fear stimuli extensively might benefit from a pharmacologic alternative. Thus, both therapeutic interventions might capitalize on memory destabilization and reconsolidation processes as primary allies in the treatment of psychiatric conditions mediated by aberrant memories. In particular, the $\mathrm{R}+\mathrm{E}$ procedure seems a promising strategy to boost CR reduction in a behavioral and noninvasive way. Future studies should, however, establish reliable online indices of fear memory destabilization, otherwise it will be difficult to translate this insight into clinical applications, because behavioral or pharmacological interventions might be applied while memory is unsusceptible to environmental influence (i.e., while merely retrieved or in an insensitive state). For example, a critical aspect of memory reactivation to achieve destabilization in this and other reconsolidation studies seems to be a prediction error (Sevenster et al. 2013; Díaz-Mataix et al. 2013; Pedreira et al. 2004). But prediction error also leads to new learning, so extended exposure results in a new memory trace (i.e., extinction learning) being established and this can lead to no effect of the intervention, or extinction learning can be the target of the intervention, as we have observed in this and previous reports. Although advances on this topic have been made by measuring online US expectancies during fear memory reactivation (Sevenster et al. 2013), further research in this direction is clearly needed to translate basic reconsolidation research to clinical settings.

\section{Acknowledgments}

This research was supported by grants from SeCyT - Universidad Nacional de Córdoba, CONICET, and Agencia Nacional de Promoción Científica y Tecnológica - FonCyT (Argentina) to V.A.M., SeCyT to A.M.B. and an ERC Consolidator Grant 648176 to T.B. The collaboration between R.I.F.M., T.B., and V.A.M. was supported by the KU Leuven Latin American Fund. R.I.F.M. was supported by a CONICET doctoral fellowship. M.M. was supported by a pregraduate SeCyT studentship.

\section{References}

Alfei M, Ferrer Monti RI, Molina VA, Bueno M, Urcelay GP. 2015. Prediction error and trace dominance determine the fate of fear memories after post-training manipulations. Learn Mem 22: 385-400.

Auber A, Tedesco V, Jones C, Monfils M, Chiamulera C. 2013. Post-retrieval extinction as reconsolidation interference: methodological issues or boundary conditions? Psychopharmacology (Berl) 226: 631-647.

Beckers T, Kindt M. 2017. Memory reconsolidation interference as an emerging treatment for emotional disorders: strengths, limitations, challenges and opportunities. Annu Rev Clin Psychol 13: 99-121.

Bouton ME. 2002. Context, ambiguity, and unlearning: sources of relapse after behavioural extinction. Biol Psychiatry 52: 976-986.

Bouton ME. 2004. Context and behavioural processes in extinction. Learn Mem 11: 485-494.

Blanchard R, Blanchard D. 1969. Passive and active reactions to fear-eliciting stimuli. J Comp Physiol Psychol 68: 129-135.

Briggs JF, Olson BP. 2013. Reexposure to the amnesic agent alleviates cycloheximide-induced retrograde amnesia for reactivated and extinction memories. Learn Mem 20: 285-288.

Bustos SG, Maldonado H, Molina VA. 2006. Midazolam disrupts fear memory reconsolidation. Neuroscience 139: 831-842.

Craske MG, Kircanski K, Zelikowsky M, Mystkowski J, Chowdhury N, Baker A. 2008. Optimizing inhibitory learning during exposure therapy. Behav Res Ther 46: 5-27.

Craske MG, Treanor M, Conway CC, Zbozinek T, Vervliet B. 2014. Maximizing exposure therapy: an inhibitory learning approach. Behav Res Ther 58: 10-23.

Das RK, Lawn W, Kambok SK. 2015. Rewriting the valuation and salience of alcohol-related stimuli via memory reconsolidation. Transl Psychiatry 5: e645.

Díaz-Mataix L, Ruiz Martinez R, Schafe G, LeDoux J, Doyére V. 2013. Detection of a temporal error triggers reconsolidation of amygdala-dependent memories. Curr Biol 23: 467-472.

Exton-McGuinness MTJ, Lee JLC, Reichelt AC. 2015. Updating memoriesThe role of prediction errors in memory reconsolidation. Behav Brain Res 278: $375-384$.

Fernández RS, Boccia MM, Pedreira ME. 2016. The fate of memory: reconsolidation and the case of prediction error. Neurosci Biobehav Rev 68: $423-441$.

Ferrer Monti RI, Giachero M, Alfei JM, Bueno AM, Cuadra G, Molina VA. 2016. An appetitive experience after fear memory destabilization attenuates fear retention: involvement GluN2B-NMDA receptors in the basolateral amygdala complex. Learn Mem 23: 465-478.

Finnie P, Nader K. 2012. The role of metaplasticity mechanisms in regulating memory destabilization and reconsolidation. Neurosci Biobehav Rev 36: 1667-1707.

Flavell CR, Lee JLC. 2013. Reconsolidation and extinction of an appetitive Pavlovian memory. Neurobiol Learn Mem 104: 25-31.

Flavell C, Barber D, Lee J. 2011. Behavioural memory reconsolidation of food and fear memories. Nat Commun 2: 504.

Fricchione J, Greenberg MS, Spring J, Wood N, Mueller-Pfeiffer C, Milad MR, Pitman RK, Orr SP. 2016. Delayed extinction fails to reduce skin conductance reactivity to fear-conditioned stimuli. Psychophysiology 53: 1343-1351.

Golkar A, Bellander M, Olsson A, Öhman A. 2012. Are memories erasable? Reconsolidation of learned fear with fear-relevant and fear-irrelevant stimuli. Front Behav Neurosci 6: 80.

Guisquet-Verrier P, Lynch J III, Cutolo P, Toledano D, Ulmen A, Jasnow AM, Riccio DC. 2015. Integration of new information with active memory accounts for retrograde amnesia: a challenge to the consolidation/ reconsolidation hypothesis? J Neurosci 35: 11623-11633.

Haubrich J, Crestani AP, Cassini LF, Santana F, Sierra RO, de Alvares Lde O, Quillfeldt JA. 2015. Reconsolidation allows fear memory to be updated to a less aversive level through the incorporation of appetitive information. Neuropsychopharmacology 40: 315-326.

Hon T, Das RK, Kamboj SK. 2016. The effects of cognitive reappraisal following retrieval-procedures designed to destabilize alcohol memories in high-risk drinkers. Psychopharmacology 233: 851-861.

Hutton-Bedbrook K, McNally GP. 2013. The promises and pitfalls of retrieval-extinction procedures in preventing relapse to drug seeking. Front Psychiatry 4: 14.

Ishii D, Matsuzawa D, Matsuda S, Tomizawa H, Sutoh C, Shimizu E. 2015. An isolated retrieval trial before extinction session does not prevent the return of fear. Behav Brain Res 287: 139-145. 
Kroon JA, Carobrez AP. 2009. Olfactory fear conditioning paradigm in rats: effects of midazolam, propranolol or scopolamine. Neurobiol Learn Mem 91: $32-40$.

Merlo E, Milton AM, Goozée ZY, Theobald DE, Everitt BJ. 2014. Reconsolidation and extinction are dissociable and mutually exclusive processes: behavioral and molecular evidence. J Neurosci 34: 2422-2431.

Misanin JR, Miller RR, Lewis DJ. 1968. Retrograde amnesia produced by electroconvulsive shock after reactivation of a consolidated memory trace. Science 160: 554-555.

Monfils M-H, Cowansage KK, Klann E, Ledoux JE. 2009. Extinction-reconsolidation boundaries: key to persistent attenuation of fear memories. Science 324: 951-955.

Nader K, Schafe GE, LeDoux JE. 2000. Fear memories require protein synthesis in the amygdala for reconsolidation after retrieval. Nature 406: 722-726.

Oyarzún J, Lopez-Barroso D, Fuentemilla L, Cucurell D, Pedraza C, Rodriguez-Fornells A, de Diego-Balaguer R. 2012. Updating fearful memories with extinction training during reconsolidation: a human study using auditory aversive stimuli. PLoS One 7: e38849.

Pedreira M, Pérez-Cuesta L, Maldonado H. 2004. Mismatch between what is expected and what actually occurs triggers memory reconsolidation or extinction. Learn Mem 11: 579-585.

Piñeyro ME, Ferrer Monti RI, Alfei JM, Bueno AM, Urcelay GP. 2014. Memory destabilization is critical for the success of the reactivation-extinction procedure. Learn Mem 21: 46-54.

Rao-Ruiz P, Rotaru D, van der Loo R, Mansvelder H, Stiedl O, Smit A, Spijker S. 2011. Retrieval-specific endocytosis of GluA2-AMPARs underlies adaptive reconsolidation of contextual fear. Nat Neurosci 14: 1302-1308.

Riccio D, Millin P, Bogart A. 2006. Reconsolidation: a brief history, a retrieval view and some recent issues. Learn Mem 13: 536-544.

Scheveneels S, Boddez Y, Vervliet B, Hermans D. 2016. The validity of laboratory-base treatment research: bridging the gap between fear extinction and exposure treatment. Behav Res Ther 86: 87-94.

Sevenster D, Beckers T, Kindt M. 2013. Prediction error governs pharmacologically induced amnesia for learned fear. Science 339: 830-833.

Sevenster D, Beckers T, Kindt M. 2014. Prediction error demarcates the transition from retrieval, to reconsolidation, to new learning. Learn Mem 21: $580-584$.

Soeter M, Kindt M. 2011. Disrupting reconsolidation: pharmacological and behavioral manipulations. Learn Mem 18: 357-366.

Urcelay G. 2012. Exposure therapy. In Exposure therapy: rethinking the modelrefining the method (ed. Neudeck P, Wittchen HU), pp. 35-63. Springer New York, New York, NY.

Urcelay GP, Lipatova O, Miller RR. 2009a. Constraints on enhanced extinction resulting from extinction treatment in the presence of an added excitor. Learn Motiv 40: 343-363.

Urcelay GP, Wheeler DS, Miller RR. 2009b. Spacing extinction trials alleviates renewal and spontaneous recovery. Learn Behav 37: 60-73.

Received February 24, 2017; accepted in revised form May 12, 2017. 


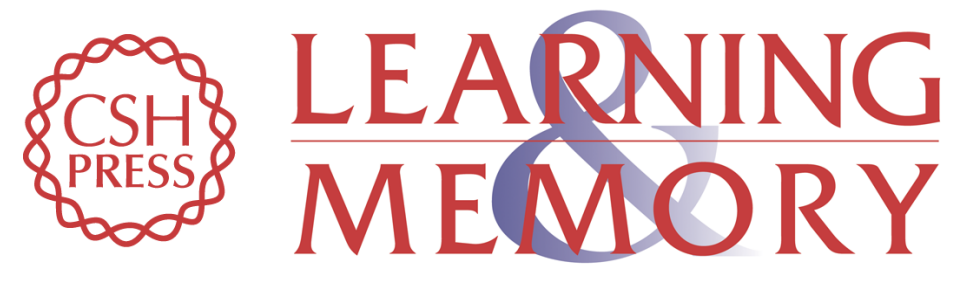

\section{A comparison of behavioral and pharmacological interventions to attenuate reactivated fear memories}

Roque I. Ferrer Monti, Joaquín M. Alfei, Matías Mugnaini, et al.

Learn. Mem. 2017, 24:

Access the most recent version at doi:10.1101/Im.045385.117

\begin{aligned} & \hline References $\begin{array}{l}\text { This article cites } 41 \text { articles, } 14 \text { of which can be accessed free at: } \\ \text { http://learnmem.cshlp.org/content/24/8/369.full.html\#ref-list-1 }\end{array} \\ & \begin{array}{r}\text { Creative } \\ \text { Commons } \\ \text { License }\end{array} \begin{array}{l}\text { This article is distributed exclusively by Cold Spring Harbor Laboratory Press for the } \\ \text { first } 12 \text { months after the full-issue publication date (see } \\ \text { http://learnmem.cshlp.org/site/misc/terms.xhtml). After } 12 \text { months, it is available under } \\ \text { a Creative Commons License (Attribution-NonCommercial } 4.0 \text { International), as } \\ \text { described at http://creativecommons.org/licenses/by-nc/4.0/. }\end{array} \\ & \begin{array}{c}\text { Receive free email alerts when new articles cite this article - sign up in the box at the } \\ \text { top right corner of the article or click here. }\end{array} \\ &$\hline\end{aligned} 